\title{
"NARRATIVA COLOMBIANA CONTEMPORÁNEA" (EDICIONES TERCER MUNDO, 1962-1967): VALOR Y CAMBIO LITERARIO DENTRO DEL ESPACIO EDITORIAL COLOMBIANO DE LOS AÑOS SESENTA*
}

* Artículo derivado del trabajo de grado "Un acercamiento al espacio editorial colombiano de los años sesenta. El caso de Ediciones Tercer Mundo (Bogotá, 1961-1970)" presentado para optar al título de Filólogo hispanista de la Universidad de Antioquia. Se inscribe dentro del proyecto "La edición del cuento colombiano en el siglo xx, Poéticas y soportes", desarrollado en el marco del grupo de investigación Colombia: tradiciones de la palabra (Universidad de Antioquia), con el apoyo del Fondo Nacional de Financiamiento para la Ciencia, la Tecnología y la Innovación "Francisco José de Caldas" (colciencias) Asimismo, se inscribe en la Estrategia de Sostenibilidad para grupos de investigación Universidad de Antioquia, UdeA 2018-2019.

Cómo citar este artículo: Penagos Jaramillo, D. (2020). "Narrativa colombiana contemporánea” (Ediciones Tercer Mundo, 1962-1967): valor y cambio literario dentro del espacio editorial colombiano de los años sesenta. Estudios de Literatura Colombiana 46, pp. 139-158. DOI: http://doi.org/10.17533/ udea.elc.n46a07

${ }^{1}$ https://orcid.org/0000-0003-1641-864X danilo.penagos@udea.edu.co

Universidad de Antioquia, Colombia

Editores: Andrés Vergara Aguirre, Christian Benavides Martínes, Vanessa Zuleta Quintero

Recibido: 15.08 .2019

Aprobado: 21.10.2019

Publicado: 27.12.2019

Copyright: $(92020$ Estudios de Literatura Colombiana. Este es un artículo de acceso abierto distribuido bajo los términos de la Licencia Creative Commons AtribuciónNo comercial - Compartir igual 4.0 Internacional

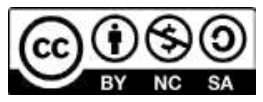

\author{
"Narrativa Colombiana Contemporánea" \\ (Ediciones Tercer Mundo, i962-ig67): \\ Literary Value and Change in Colombian \\ Publishing Space During i 960 Decade
}

Danilo Penagos Jaramillo ${ }^{1}$

Resumen: este artículo estudia la colección "Narrativa colombiana contemporánea" editada por Ediciones Tercer Mundo durante los años sesenta y muestra su importancia para la literatura colombiana en la segunda mitad del siglo xx. Una mirada a la historia de la colección da cuenta de cómo la crítica literaria legitimó las obras y los escritores que fueron publicados en esta. Esto significó una ruptura en la valorización de la literatura nacional y, con el paso de los años, la consagración de algunos autores en manuales e historias literarias.

Palabras clave: "Narrativa colombiana contemporánea"; Ediciones Tercer Mundo; estudios editoriales; literatura colombiana; edición en Colombia.

Abstract: This article studies the "Narrativa Colombiana contemporánea" series, published by Ediciones Tercer Mundo in 1960 decade, and its importance for the Colombian literature in the second half of the twentieth century. A look to the series' history shows how the literary critic legitimated the works and the authors published in the series. This fact meant a rupture in the appreciation of national literature and the some authors' consecration, especially in manuals and literature histories, throughout the years.

Keywords: "Narrativa colombiana contemporánea"; Ediciones Tercer Mundo; Publishing Studies; Colombian Literature; Colombian Publishing. 


\section{Introducción}

Con la desaparición de Mito (1962) —mas no de sus epígonos-, la puesta en escena del movimiento nadaísta (1958-1971), el resquebrajamiento de las relaciones entre la Academia Colombiana de la Lengua y el campo literario, y con lo que se podría denominar como la paulatina internacionalización de los autores nacionales, los años sesenta significaron para la literatura colombiana un cambio de época. Se gestó en ese momento una actualización de los presupuestos estéticos y los referentes culturales, lo que derivó en la transformación de unos valores literarios que encontraron en la novela y en la narrativa, en general, su mejor medio de expresión (Llano Parra, 2015; Marín Colorado, 2017; Rodríguez Amaya, 2014, Williams, 1991). Al mismo tiempo, la búsqueda de una estética pura y la afirmación "contundente" y "consciente” de la autonomía intelectual fueron las tomas de posición que constituyeron una nueva realidad para el escritor colombiano durante esa década (Marín Colorado, 2017, p. 139).

En 1960, con su célebre artículo "La literatura colombiana, un fraude a la nación” Gabriel García Márquez (1983) había señalado el desaliento del escritor contemporáneo por las pocas posibilidades que le brindaba el medio y, más importante aún, la escasa producción de literatura colombiana que, según él, solo había tenido "la única explosión literaria de legítimo carácter" con la literatura de la época de la Violencia (p. 313). Dicha literatura, narrativa en casi toda su extensión, había marcado un esfuerzo por dejar atrás la Colombia de poetas y humanistas, parte de un pasado fraudulento y falsificado. Empero, a esta le faltó proyección universal y eran muy pocos los escritores que podían hacer su trabajo con independencia y dedicación. Ejercer el oficio de manera profesional era una situación condicionada, entonces, por la ausencia de editoriales nacionales que apostaran por un proyecto de publicación consistente e internacional y que dinamizaran un campo literario que se oponía a la transformación de los valores literarios, pues hasta ese momento la estructura sociocultural "estaba consolidada y oponía fuerte resistencia al cambio y a la renovación de personas y temas en la literatura" (Torres León, 1964, p. 1290).

La modernización de las letras colombianas se convirtió, de este modo, en una prioridad. Una gran parte de los agentes del campo literario y editorial, esto es, 
autores, editores, libreros, críticos y lectores, estaba atenta ante la aparición de nuevas ideas y tendencias en la producción, reconociendo y legitimando la transformación de lo literario. Con la publicación de la colección de "Narrativa colombiana contemporánea" (1962-1967), la edición del libro Problemas y perspectivas de la novela americana (1964) de Uriel Ospina, diversos artículos sobre narrativa y cuentos publicados en Tercer Mundo. Gaceta Mensual (1964-1970), además del patrocinio al Concurso Nadaísta de Novela (1966) y la promoción de un "frustrado" premio nacional de novela y ensayo (1966), Ediciones Tercer Mundo certificaba la necesidad de renovación y cambio dentro de las letras colombianas. La red de distribución y las estrategias comerciales de la editorial bogotana alcanzaron un mercado local e internacional que soportaba su presupuesto inicial, esto es difundir el pensamiento colombiano con un nuevo repertorio de textos. En esta medida, para Raymond L. Williams (1991), el surgimiento de empresas como Tercer Mundo "permitió a los novelistas colombianos dirigirse a un verdadero mercado nacional, en vez del regional, e inclusive, por primera vez, al público internacional" (p. 69).

\section{Narrativa, colombiana y contemporánea. Hacia una caracterización de la colección}

En 1962 Ediciones Tercer Mundo inauguró la publicación de la colección "Narrativa colombiana contemporánea”. Con trece títulos editados hasta 1967 , como se puede observar en la Tabla 1, esta colección se presentó en un formato de libro de bolsillo $(17 \times 13 \mathrm{~cm})$, en rústica, papel bond ahuesado y un precio promedio de $\$ 16$ pesos. Allí se publicaron los tres principales géneros narrativos — seis novelas, dos libros de cuento, un libro de viajes y uno de crónica-, dos libros pertenecientes al género dramatúrgico y un libro clasificado por la misma editorial como "humorismo". Cuatro de los libros eran ilustrados o incluían fotografías en su interior, la mayoría tuvo una ilustración en su carátula, solo uno superó las 300 páginas y las novelas tenían el precio más elevado (entre $\$ 17$ y $\$ 25$ pesos). Es importante subrayar que solo en algunos casos específicos (en Respirando el verano, y El hombre que hacia monitos, por ejemplo) se presentaron prólogos o paratextos críticos o apreciativos que informaron al lector sobre los autores o que le brindaron una mirada global alrededor de la obra. 
“Narrativa colombiana contemporánea” (Ediciones Tercer Mundo, i 962-i 967): valor y cambio literario...

\begin{tabular}{|c|c|c|c|c|c|c|c|c|c|c|c|c|c|}
\hline 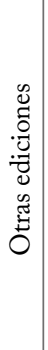 & 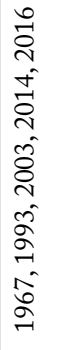 & 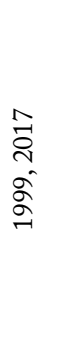 & 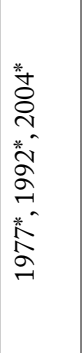 &  & 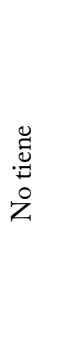 & 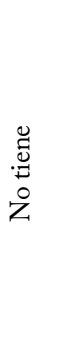 & 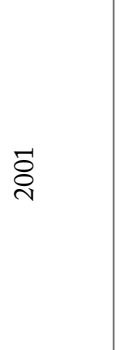 & 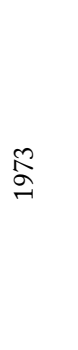 & 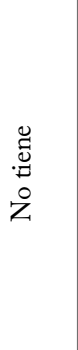 & 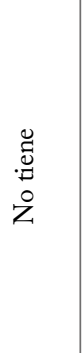 & 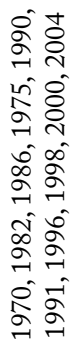 & 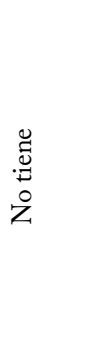 & 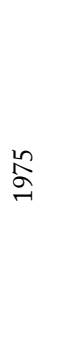 \\
\hline 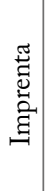 & 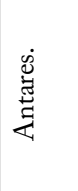 & $\begin{array}{l}\dot{\vec{j}} \\
\dot{\text { s }}\end{array}$ & 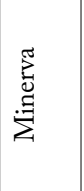 & 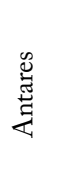 & 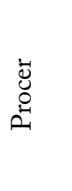 & 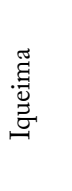 & $\begin{array}{l}\dot{j} \\
\dot{s}\end{array}$ & 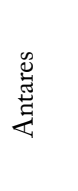 & $\begin{array}{l}\dot{j} \\
\dot{s}\end{array}$ & 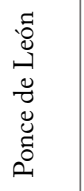 & 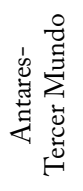 & $\begin{array}{l}\dot{j} \\
\dot{s}\end{array}$ & 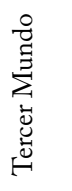 \\
\hline  & $\stackrel{\pi}{a}$ & 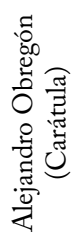 & $\stackrel{\pi}{a}$ & $\stackrel{\pi}{a}$ & $\stackrel{\pi}{a}$ & 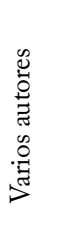 & 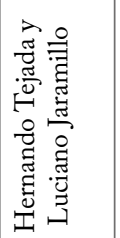 & 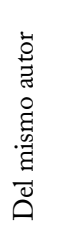 & 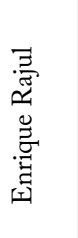 & $\begin{array}{l}\dot{\vec{s}} \\
\dot{\text { s }}\end{array}$ & $\stackrel{\pi}{a}$ & $\underset{\dot{s}}{\dot{s}}$ & $\stackrel{\pi}{a}$ \\
\hline 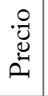 & 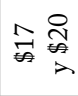 & $\begin{array}{l}\dot{j} \\
\dot{\omega}\end{array}$ & $\stackrel{n}{20}$ & $\stackrel{\text { Ln }}{\stackrel{n}{6}}$ & $\underset{\Delta}{\stackrel{ \pm}{*}}$ & $\stackrel{n}{n}$ & $\stackrel{m}{\leftrightarrows}$ & $\stackrel{m}{m}$ & $\stackrel{m}{\stackrel{7}{*}}$ &  & 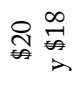 & $\underset{\infty}{\infty}$ & $\begin{array}{l}\stackrel{\sim}{\sim} \\
\text { }\end{array}$ \\
\hline 芯 & $\begin{array}{l}\frac{\pi}{0} \\
\stackrel{0}{0}\end{array}$ & 苞 & $\stackrel{\stackrel{\Xi}{\leftrightarrows}}{\oplus}$ & $\begin{array}{l}\frac{\pi}{0} \\
\stackrel{0}{0} \\
z\end{array}$ & 苞 & 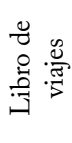 & 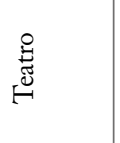 & 节 & 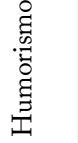 & $\begin{array}{l}\frac{\pi}{00} \\
\stackrel{0}{0} \\
z\end{array}$ & $\begin{array}{l}\frac{\pi}{00} \\
\text { है } \\
\text { Z }\end{array}$ & $\begin{array}{l}\frac{5}{0} \\
\text { 己े } \\
\text { Z }\end{array}$ & 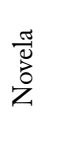 \\
\hline مَّْ & $\hat{\text { }}$ & $\overrightarrow{\widetilde{N}}$ & $\vec{\sim}$ & 官 & $\stackrel{+}{\sigma}$ & $\hat{)}$ & $\stackrel{゚}{\underset{\sim}{~}}$ & ભે & $\stackrel{\vec{m}}{\sim}$ & $\stackrel{+}{\rightarrow}$ & 옴 & $\stackrel{\circ}{+}$ & $\begin{array}{l}\operatorname{Ln} \\
\stackrel{2}{n}\end{array}$ \\
\hline 芶 & 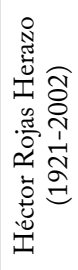 & 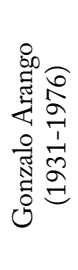 & 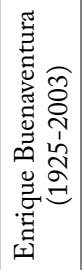 &  & 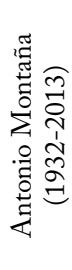 & 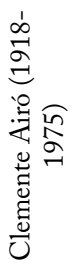 & 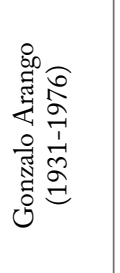 & 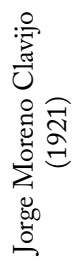 & 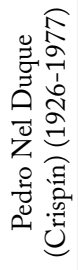 & 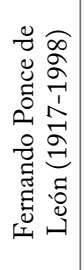 &  & 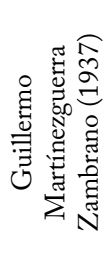 & 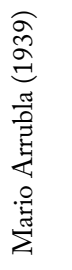 \\
\hline 案 & స్ర & $\begin{array}{l}\text { } \\
\stackrel{-}{-}\end{array}$ & ڤై & $\begin{array}{l}\text { } \\
\stackrel{\sigma}{-}\end{array}$ & $\begin{array}{l}\text { } \\
2\end{array}$ & $\begin{array}{l}\text { ఫ̊ } \\
\stackrel{-}{\sim}\end{array}$ & ఫু & $\begin{array}{l}\text { ఫ̊ } \\
\stackrel{్}{~}\end{array}$ & $\begin{array}{l}\text { ఫ̊ } \\
\text { ন }\end{array}$ & ஜㅇ & $\begin{array}{l}\stackrel{\circ}{-} \\
\stackrel{-}{-1}\end{array}$ & $\begin{array}{l}\stackrel{2}{二} \\
\stackrel{2}{-1}\end{array}$ & 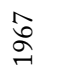 \\
\hline 总 & 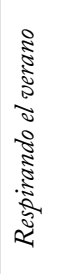 &  & 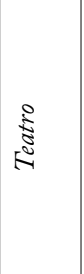 & 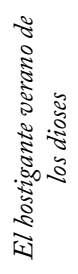 & 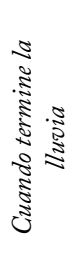 & 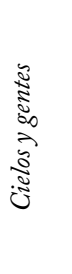 & 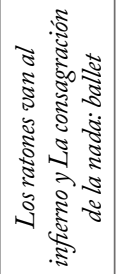 &  & 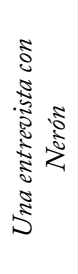 &  & 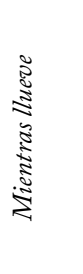 & 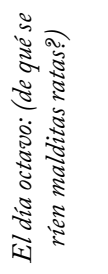 & 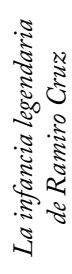 \\
\hline
\end{tabular}


Durante los primeros seis años de publicación y crecimiento constante de la editorial, la edición de literatura siempre tuvo un lugar importante dentro de un catálogo que se pensaba ecléctico y amplio. Entre 1961 y 1967 se publicaron 177 títulos, de los cuales 35 (20\%) eran obras literarias. Cifra no menor, si se considera que los estudios que han trabajado Tercer Mundo en otras oportunidades (en especial Llano Parra, 2015) han señalado que la literatura ocupó un lugar mínimo dentro de un catálogo dedicado a las ciencias sociales y humanas. De estas 35 obras, 13 (7,3\%) hicieron parte de la colección de narrativa, y aunque en tan poco tiempo no se pueda hablar de una regularidad en su ritmo de publicación, esta colección significó más de la mitad de libros literarios ofrecidos por Tercer Mundo en sus librerías como editor.

Los otros libros de literatura publicados en el mismo periodo serían las 6 obras de la colección "Caballito de mar" y 17 títulos que pertenecían a otras colecciones, como Viaje a pie (1967), o que se imprimían por encargo en los talleres de la editorial y luego eran distribuidos. De este último grupo se destacan las novelas de J. J. García: Diálogos en la reina del mar: novela policiaca (1965) y Rufo, gobernador (1966). Otros dos casos particulares de obras narrativas que no se incluyeron dentro de la colección y que merecen un estudio pormenorizado, porque demuestran la predisposición de la editorial por un género que cobraba auge dentro la literatura colombiana y que corría, según Airó (23 de febrero de 1963), "a la conquista de la cabeza del hacer literario" (p. 1), fueron, por un lado, las novelas ganadoras del Concurso Nadaísta de Novela (1966), a saber: Terremoto de Germán Pinzón, Los días más felices del año de Humberto Navarro Lince y La pequeña hermana de Pablus Gallinazo. Y, por otro, el libro Cuentos (1966) del escritor caleño Hernán Hoyos, de quien se proyectaba editar, según la contracubierta del libro, "una serie de libros de ficción" dentro de los cuales se contaban las novelas: Todos nos condenamos, Aquella vieja fantástica y El bruto. ${ }^{1}$

Ahora bien, la seña de identidad de la colección "Narrativa colombiana contemporánea" fue la preocupación por difundir escritores colombianos. Aunque esta ya era la preocupación general de todo el proyecto editorial, en este caso la opción fue editar nuevos autores cuya obra narrativa estuviera inédita o, en su defecto, autores que

1 Hasta el momento no se tienen indicios de por qué no se editaron finalmente estos libros en Tercer Mundo. Lo que sí se puede constatar es que de las tres novelas anunciadas: El Bruto fue publicado en Cali con el título El bruto y las lesbianas en 1971 por la tipografía Ediciones Exclusivas, donde Hoyos además publicaría la mayoría de sus obras. 
representaran un valor distintivo dentro del panorama literario nacional contemporáneo. Con esta decisión, la editorial definía su participación dentro del mercado literario colombiano y encaminaba su catálogo hacia un enriquecimiento del repertorio de textos dedicados a la narrativa. Al mismo tiempo, entregaba al lector obras que se suponían medida y formación del gusto estético. La etiqueta "Narrativa colombiana contemporánea” definía una unidad de significado que representaba las tendencias literarias de la época y presumía una comunidad de lectores interesada en la renovación del material de lectura tanto en el contenido como en la materialidad misma del texto. No era gratuito entonces que estas obras se presentaran en formato de bolsillo e ilustradas en sus portadas o en su interior por artistas de prestigio en ese momento. Esto habla de una apuesta editorial consciente de conquistar un mercado o una comunidad de lectores cuyas expectativas y gusto literario se estaban decantando por lo narrativo.

\section{La colección: un lugar para la promoción y el reconocimiento}

Los autores publicados se caracterizaron por tres asuntos puntuales. En primer lugar, porque casi todos eran menores de 40 años y ninguno llegaba a los 50 años a la fecha de publicación de su primera obra en la colección. Eran, pues, autores en ejercicio. En segundo lugar, porque más de la mitad había nacido fuera de Bogotá. Y, en tercer lugar, porque la mayoría estaba publicando su primera obra narrativa o publicaba obras inéditas.

Con la publicación en 1962 de Respirando el verano, primera novela del hasta ese momento poeta y pintor Héctor Rojas Herazo (Tolú, 41 años), ganador en el año anterior del segundo puesto en el primer concurso de novela patrocinado por la empresa Esso, se instituía una plataforma para la promoción y el reconocimiento de nuevos valores literarios. En 1963, la aparición de Sexo y saxofón de Gonzalo Arango (Andes, 32 años) ratificaba el plan. La figura tutelar del movimiento nadaísta hasta ese momento solo había publicado los textos programáticos de su movimiento, y su propuesta narrativa y estética no había tenido editor. En ese mismo año aparecerían en el catálogo la ópera prima de la novel escritora Fanny Buitrago (Barranquilla, 20 años), El hostigante verano de los dioses; el libro de cuentos Cuando termine la lluvia de Antonio Montaña (Bogotá, 31 años), profesor de la Universidad 
de los Andes y ganador del concurso de cuento organizado por la Secretaría de Educación en 1959, y una compilación de obras dramatúrgicas del actor, director y teórico del teatro colombiano Enrique Buenaventura (Cali, 38 años). ${ }^{2}$

Estos primeros textos señalaban un derrotero de lo que pretendía la editorial, promocionando nombres específicos. A excepción de Montaña, todos eran autores de la "provincia", lo que demuestra de entrada un cuestionamiento directo al centralismo literario, criticado unos años antes por García Márquez. Asimismo, Arango, Buitrago y Rojas Herazo marcaron tendencia dentro del movimiento de renovación de las letras colombianas durante los sesenta. Simpatizantes de las ideas promovidas por el nadaísmo, Buitrago y Rojas Herazo iban a ser antologados en los libros de Arango intitulados 13 poetas nadaistas (1963) y De la Nada al Nadaísmo (1966), la primera por convicción y el segundo por adopción. ${ }^{3}$ Su inclusión en la colección se justificaba, entonces, por ser Buitrago una promesa de las letras colombianas, y Arango y Rojas Herazo, por ser el presente de una literatura que estaba en crisis.

Para 1964 la inclusión del libro de viajes, Cielos y gentes, del exiliado español Clemente Airó (Madrid, 46 años) definió un nuevo matiz para la colección. Airó en ese momento era un reconocido novelista, editor y crítico de arte, que había promovido con sus proyectos editoriales un espacio para la publicación de narrativa sobre la Violencia; su estatus dentro del campo le daba, en esta medida, credibilidad y legitimaba unos modos específicos del quehacer literario, ya que su trabajo había significado "una renovación en los temas, las técnicas y, en las mismas formas estéticas que circulaban en la época” (Pérez, 2018, p. 114). Es importante resaltar que con la inclusión de Airó también se ponía en cuestión el carácter nacionalista del adjetivo "colombiano", pensado como algo inherente a los escritores que nacieron en el país. Si se entiende que la literatura y el arte "no se comprenden por denominaciones de 'origen' fijas”(Bejarano,2017,p.103), Airó podía hacer parte de la colección, pues había orientado desde un principio su obra hacia la comprensión de la realidad nacional como realidad humana y universal, y era considerado como un escritor propiamente

2 Las obras que componían el libro Teatro de E. Buenaventura eran: Un réquiem por el padre de las Casas, La tragedia del rey Cristophe y En la diestra de Dios Padre. Todas ellas parte del canon actual del teatro colombiano (Ver Teatro colombiano contemporáneo. Antología de González Cajiao).

3 El revelador estudio de Llano Parra (2015) sobre el movimiento nadaísta y su influencia en el campo cultural de los años sesenta cuenta de una manera más detallada esta relación. 
colombiano, pues a pesar de su procedencia, ya había sido incluido en los listados de novelistas colombianos de la época (Bronx, 1966; Madrid Malo, 1966; Ospina, 1976).

En el mismo año salían al mercado las obras Los ratones van al infierno y La consagración de la nada: ballet de Gonzalo Arango, quien ya tenía una puerta abierta en las publicaciones periódicas culturales del país y publicaba por segunda vez en la colección; Una entrevista con Nerón, texto de carácter humorístico, del periodista caldense Pedro Nel Duque, Crispín (Aránzazu, 38 años) y El hombre que hacía monitos del caricaturista y periodista Jorge Moreno Clavijo (Bogotá, 43 años), quizás el único reaccionario de todos los autores publicados dentro de la serie y en cuyas crónicas se sentía un dejo de nostalgia por la Bogotá letrada. Estos autores, reconocidos por sus labores en los medios de comunicación impresa y en el campo cultural, le daban a la colección un carácter dinámico y amplio, pues sus textos - libro de viajes en el caso de Airó, crónica en Clavijo y "humorismo" en el de Duque - ponían el acento en la posibilidad de diversificar la colección. Cabe señalar que, en términos materiales, estas obras también significaron un cambio en la presentación de "Narrativa colombiana contemporánea", ya que fueron las únicas, junto con Sexo y saxofón, que incluyeron ilustraciones o fotografías, lo que implicaba una nueva propuesta de lectura para el lector.

El cierre de esta primera etapa de la colección se hizo publicando en 1966 y 1967 a cuatro novelistas, dos de ellos ya reconocidos por obras publicadas en otras editoriales: Fernando Ponce de León (Bogotá, 47 años), quien ya había publicado cuatro novelas, una de ellas Matías (1958), considerada una las primeras novelas urbanas en Colombia y que además fue censurada, y Fernando Soto Aparicio (Socha, 33 años); este último colaborador de la Tercer Mundo. Gaceta Mensual y joven promesa del mercado literario nacional, pues se convirtió en uno de los autores más editados durante la segunda mitad del siglo xx. Los otros dos autores, Guillermo Martínezguerra (s. d., 29 años) y Mario Arrubla (Medellín, 28 años), quizás unos desconocidos para la historia literaria, serían las apuestas más arriesgadas en esta tarea de promoción de nuevos autores, ya que a diferencia de Buitrago, que se movía en el círculo nadaísta y cuyos cuentos eran divulgados en diversas publicaciones periódicas de la época, y Montaña, que había ganado el premio de cuento referido, ninguno de los dos autores tenía una credencial de presentación dentro del campo literario y a la larga serían escritores de una sola novela. 


\section{De la novela al teatro: una colección de literatura}

Los géneros literarios conocen sus épocas de moda y los tiempos que corren parecen ser más propicios para la novela, el cuento y el teatro (Moreno Clavijo, $196_{3}$, p. 5 ).

A partir de la tipología de géneros — novela, cuento, relato de viaje, crónica, teatro y humorismo-, es posible segmentar la colección en tres grupos de textos: el primero de ellos definido por la narrativa de ficción; el segundo, por la narrativa de tipo periodístico, y, el último, por los textos dramatúrgicos.

En la cubierta de Respirando el verano, la editorial catalogaba la novela como la primera de una serie que se titulaba "Ficción", y en la contracubierta se indicaba que con este libro la editorial iniciaba "su galería de ficción moderna en Colombia”. Hasta aquí, se proyectaba un plan de publicación orientado por unos textos cuyas características principales serían la ficción y lo moderno. ${ }^{4}$ Este plan se certificó con la edición de las otras cinco novelas, los dos libros de cuento y los textos dramatúrgicos. No obstante, no hay información que dé cuenta del cambio en el nombre propuesto inicialmente: "Ficción”, y del nombre con que se publicitó la colección a partir de 1963. Se puede intuir que el nombre "Narrativa colombiana contemporánea" les brindaba a los editores la posibilidad de crear una serie con mayor flexibilidad ante una posible ausencia de manuscritos para su publicación. Asimismo, dicho título permitiría ampliar la serie a otros textos de interés y que representaran una novedad para el público lector, como efectivamente ocurrió con los libros de crónica y humorismo, narrativa de tipo periodístico que significó un cambio en la colección, publicando autores que por su reconocimiento en el campo cultural podrían tener una acogida mayor dentro del mercado.

Empero, había otro problema: cómo leer las obras dramatúrgicas incluidas dentro de una colección de narrativa. Dentro del plan inicial, ya se ha dicho, estas obras clasificaban como ficción y, además, eran parte de la modernización de la 
dramaturgia colombiana (ver nota 2). Los aires de renovación que se pretendían con la colección respaldaban la edición de estas dos obras, pues con ellas se promocionaban dos autores cuyo trabajo ya era apreciado como vanguardista. Para Eduardo García Piedrahita (1963), "la literatura teatral" tenía una doble virtud, "la de atraernos desde la butaca del teatro y desde el sillón de la biblioteca”(p. 5). Editar una obra dramatúrgica era, entonces, posibilitar una doble experiencia con el texto literario. Se podría decir que con la inclusión de estas obras, los editores ponían en las manos del lector una propuesta de lectura novedosa, ya que estos libros se etiquetaban con un paratexto que los definía como narrativos y hacían parte de un conjunto de obras cuya esencia era el relato. Al mismo tiempo, los editores validaban de este modo su apoyo a la difusión del teatro experimental colombiano (en la Tercer Mundo. Gaceta mensual se publicaron varios artículos alrededor de la escena dramatúrgica colombiana) y legitimaban nuevas formas de lo literario, propiciando de este modo su evolución.

\section{Recepción, consagración y canonización de una colección literaria}

Proponer un acercamiento a la recepción, consagración y canonización de las obras incluidas en "Narrativa colombiana contemporánea" exige, por un lado, observar el contexto de publicación de las obras, haciendo un balance de las ventas que tuvieron los libros y de los comentarios que circularon en publicaciones periódicas de la época acerca de los títulos editados en la serie de narrativa. Por otro, dar cuenta de la presencia de estas obras en la historia literaria a partir de estudios críticos, manuales de literatura y otras ediciones de las obras. A continuación se presentan algunas líneas generales y ejemplos sobre los hallazgos de este balance.

\section{In illo tempore: "una respiración literaria novedosa"}

Durante los años sesenta, ya se ha dicho, la producción literaria se orientó hacia lo narrativo. Editar y publicar una novela o un libro de cuentos fue una toma de posición dentro del campo editorial y literario en esa década. La crítica literaria y las publicaciones periódicas estuvieron atentas a estas nuevas formas de expresión y con su trabajo permitieron que en sus páginas circularan juicios críticos y apreciativos 
sobre el deber ser de la novela o el cuento, polémicas sobre los premios literarios especializados en el género, balances históricos sobre la narrativa en el país y múltiples reseñas sobre los libros que iban apareciendo año tras año.

En términos económicos, las ventas también determinarían cuál era el éxito de un libro; no obstante, ante la falta de estos datos en el archivo disponible para la investigación es muy difícil conocer con detalle lo que sucedía al respecto. Se sabe, eso sí, que los ejemplares de Sexo y saxofón y El hostigante verano de los dioses se agotaron rápidamente (según el catálogo de la editorial publicado en Tercer Mundo. Gaceta Mensual), lo que hace suponer una inclinación del lector por ciertas formas narrativas, cuyo impulso se veía respaldado, según Humberto Bronx (1966), por un público que ya estaba formado ("estudiantes universitarios") y que prefería "la novela corta, de cualquier tema, preferentemente amoroso, costumbrista, realista, sociológico y sobre todo policiaco" (p. 6). En este contexto, las novelas y los cuentos de la colección serían los más reseñados y a los que primero les llegaría la consagración, por medio de la crítica y la academia, entendidas estas últimas, en términos de Jacques Dubois (2014), como instancias "que aseguran la circulación de las obras y su 'buen uso" y cuya función principal es "asumir la legitimidad literaria y reproducirla mediante el crédito cultural que le otorgan al producto y a los agentes de la producción” (p. 74).

En 1963, se publicó en Lecturas Dominicales una reseña de los cuatro últimos libros de Tercer Mundo. Allí, Jorge Moreno Clavijo (1963) daba cuenta de Sexo y saxofón, El hostigante verano de los dioses, Cuando termine la lluvia y Teatro, y señalaba que con estos libros la editorial incorporaba "la obra fresca, fuerte y valerosa, de cuatro jóvenes escritores identificados bajo un signo común: el inconformismo” (p. 5). La novedad estaba garantizada. Se inauguró con estos escritores, como ya se ha dicho, una colección cuya tarjeta de presentación era la publicación de autores que tenían un lenguaje "de innegable valor expresivo" y se ubicaban "en el terreno de la originalidad" (p. 5). La opinión de Moreno Clavijo se veía refrendada con las reseñas que aparecían en el Boletín Cultural y Bibliográfico del Banco de la República. En esta publicación se destacó, por ejemplo, que la joven escritora Fanny Buitrago demostraba "originalidad y brillo" con su novela y trataba de "constituirse en un testigo de su tiempo", integrándose a un grupo de novelistas que "escriben airados contra los dioses, las tumbas y las memorias” (Rodríguez Garavito, 1963b, p. 839). Buitrago y su obra 
se perfilaban, según estos comentarios, como "testimonio, documento y valor de la narrativa colombiana contemporánea” (Moreno Clavijo, 1963, p. 5).

Del segundo grupo de textos que aparecieron en la colección "Narrativa colombiana contemporánea" se pueden encontrar elogiosas reseñas de Cielos y gentes, de Los ratones van al infierno y de Una entrevista con Nerón. Del libro de viajes de Airó, señalaba Fernando Soto Aparicio (1964) en la sección de "Libros contemporáneos", del Magazín dominical de El Espectador, la novedad y grata experiencia de lectura que tuvo con este libro, en tanto este se había “separado de los libros de viajes románticos, llenos de 'saudade"' (p. 15b) y había hecho, como un buen novelista, un retrato social de la época. De otro lado, para Rodríguez Garavito (1964b), reseñista del Boletín, "Una entrevista con Nerón [era] sencillamente admirable" que por su humor y su gracia constituía un "magnífico libro" que recomendaba a sus lectores, pues su autor, era "dueño de una cultura que dosifica y diversifica" (p. 1424). Por último, en la reseña de Los ratones van al infierno, Rodríguez Garavito (1964a), además de comentar la obra, ponía énfasis en la actividad del autor, quien según él tenía "ganado un sitio de altura dentro del cuadro de las letras jóvenes de Colombia” (p. 818). Con esta obra Arango marcaba "la aparición en la literatura colombiana, de un nuevo estilo, que [era] preciso señalar como un acontecimiento” (Rodríguez Garavito, 1964a, p. 818). Representaba "una respiración literaria novedosa, no sometida a viejos cánones y patrones gramaticales de una gris inercia expresiva" y eran "relatos" que "evidencia[ban] una firme vocación creadora y animadora” (p. 818) de los nuevos valores literarios.

Si se detalla en las reseñas y comentarios hasta aquí mencionados, se puede ver que la mayoría de las veces estos tendían a hacer una apología de la obra. Dicha tendencia a la lisonja y al aprecio conformaría lo que Pierre Bourdieu llama "sociedad de admiración mutua”, que empieza a legitimar y transmitir unos valores literarios específicos, en este caso los que se proponen desde el proyecto editorial de Ediciones Tercer Mundo. No es gratuito, entonces, que Moreno Clavijo o Soto Aparicio, por ejemplo, sean autores de un libro para la colección, a la vez que reseñistas de alguno de sus libros.

Hay que anotar, sin embargo, que no todo eran elogios; algunas de las obras también se vieron sometidas a una crítica que las desdecía. La infancia legendaria de Ramiro Cruz de Mario Arrubla apareció en el Boletín Cultural y Bibliográfico con un comentario que no la dejaba bien parada frente a las demás obras de la colección. 
Para Rodríguez Garavito (1967), la novela estaba "difuminada, carente de fuerza [y] sin logros vitales” (p. 126). El autor había, según el crítico, obtenido el "mecenazgo" de Tercer Mundo - Arrubla fue redactor de la Tercer Mundo. Gaceta Mensualpara publicar un malogrado texto que solo era una "aproximación a una novela", con la que no salía "muy bien librado" (p. 126). Lo animaba, eso sí, a continuar su labor, pero como se ha dicho, La infancia legendaria de Ramiro Cruz sería la única obra literaria que publicaría Arrubla, quien terminó siendo más reconocido por su labor como historiador y dinamizador de la nueva izquierda en Colombia.

Otro de los ejemplos y el caso más notable, quizá, por lo paradójico que resulta es el de Respirando el verano. Esta novela, que había sido finalista del concurso de novela Esso, que representaba el inicio de la colección, "que estaba emparentada innegablemente con la mejor narratoria del momento" y que tenía todo "el derecho a trascender" (Lecturas dominicales, 1963, p. 4), fue blanco de críticas muy severas tan pronto fue publicada. El primero que lanzó un dardo contra la obra de Rojas Herazo fue Hernando Téllez. Su lectura de la novela le dio pie para publicar un artículo donde se preguntaba qué se debía hacer con Rojas Herazo, dónde ponerlo dentro del panorama literario contemporáneo. A pesar de su talento, para el crítico la figura del escritor costeño dejaba una "impresión indecisa entre la admiración y la reserva" (Téllez, 1963, p. 7), ya que su obra no respondía a las exigencias del género novelístico y abusaba de su capacidad como poeta. Téllez sustentaba, desde una lectura clásica de la novela, que "los méritos literarios de esta obra no configura[ban] los de un novelista, no logra[ban] constituir ese resultado, tan difícil de precisar y definir, que es una novela" (p. 7); y ante la pregunta por la calidad de la obra y la capacidad del autor como novelista, respondía que a su juicio "Rojas Herazo me parece ser un magnífico poeta, un pintor mucho menos importante que el poeta y un novelista de vocación discutible” (p. 7). En esta misma tónica Rodríguez Garavito (1963a), en el Boletín, decía que "la técnica novelística" del poeta no era aceptable, pues este no "sab[ía] distinguir los géneros", "se deja[ba] llevar por el lirismo" (p. 251) y si continuaba escribiendo este género debía, en su opinión, "realizar una paciente labor de poda" (p. 251). Lo paradójico del asunto estaba, pues, en que un año más tarde Rojas Herazo sería considerado por otra parte de la crítica como uno de los narradores más importantes de la década, como 
se verá a continuación. Su trabajo, a su vez, se consagraría con En noviembre llega el arzobispo y la obtención del premio de Novela Esso, en 1967.

Dicho esto, la otra crítica que dio cuenta de las obras de la colección sería una crítica literaria de cuño historiográfico y bibliográfico. Esta apreciaba las obras literarias desde una perspectiva diacrónica, haciendo balances de la producción narrativa colombiana. El primero de estos estudios fue Dos horas de literatura colombiana de Javier Arango Ferrer (1963), en el que Respirando el verano aparece como un "novísimo relato" (p. 84) que por sus características no tenía antecedentes en la literatura colombiana. La prematura inclusión de Rojas Herazo como narrador en un texto que agrupaba la producción literaria en la historia del país y que hacía las veces de referencia no era un hecho menor. Con una sola novela ya se consagraba como uno de los narradores colombianos de todas las épocas y su novela se abría paso con los clásicos del momento. En 1966, dos estudios de la narrativa nacional en los últimos veinticinco años harían las veces de jueces para las novelas publicadas en la colección. El primero de ellos, "Estado actual de la novela en Colombia", fue publicado en dos partes en el Boletín Cultural y Bibliográfico por Néstor Madrid Malo (1966), quien consideraba que Rojas Herazo "insurgió en los terrenos de la novela [...] porque [había llegado] de pronto casi subversivamente, al panorama novelístico colombiano con un libro hermoso y crepitante" (p. 1131). Esta irrupción era una muestra de la capacidad del escritor - “clarividencia intelectual y artística”, según Madrid Malo (1966, p. 1131) — en el ámbito narrativo y los aires de renovación que traía su obra para la literatura colombiana. En Veinte años de novela colombiana, Humberto Bronx (1966) argumentaba que desde 1962 soplaban “aires nuevos sobre la mente de los novelistas colombianos, por cuanto se ha ido abandonando casi del todo el tema cansado y excesivamente apasionado de la violencia” (p. 25). Según el autor, con el estímulo de premios y el apoyo de las nuevas editoriales (Tercer Mundo, entre ellas), se empezaban a publicar novelas sin antecedentes en Colombia, como La mala hora, La casa grande y Respirando el verano.

En el estudio de Madrid Malo (1966), el cuadro de producción novelística de esos últimos veinticinco años se cerraba con "las más jóvenes figuras en este campo y, por lo tanto, de promisorias realizaciones” (p. 1132), a saber: Fernando Soto Aparicio y Fanny Buitrago. El primero, que en 1962 había ganado un premio en España por 
su libro La rebelión de las ratas, de "forma original" actualizaba la novela de tipo social, exitosa ya por la producción novelística de José Antonio Osorio Lizarazo. La segunda, era "un caso de precocidad poco común", a la que por su "seriedad más que madura y sagaz", el crítico le auguraba que "llega[ría] bien lejos por este camino azaroso del novelar" (p. 1132).

Así las cosas, la validación de unas formas específicas de concebir y hacer la literatura, "huyendo del lugar común, de las situaciones manoseadas" le habían permitido a la editorial con la colección "Narrativa colombiana contemporánea" ofrecer "en estos libros de exigente gusto editorial un aporte de singular valor a las letras colombianas" (Moreno Clavijo, 1963, p. 5). Tanto así que cuatro de sus autores rápidamente formaron parte del "núcleo más descollante" de escritores que, según Madrid Malo (1966), "asegura[ban] la plena y eficaz presencia de Colombia en el conjunto de la novela latinoamericana" (p. 1132) de la época. Este grupo se constituía

- [...] por los novelistas de primera línea: Mejía Vallejo, Zapata Olivella, García Márquez, Santa, Ponce de León, Soto Aparicio, Cepeda Samudio, Rojas Herazo, Fanny Buitrago - tanto por la calidad de la obra ya realizada como por las especiales dotes que para el cultivo de ese género han demostrado poseer todos ellos (p. II32).

\section{Statu quo}

Un acercamiento a los manuales de literatura, a las historias de la narrativa colombiana y estudios críticos desde la academia permiten constatar que algunas de las obras editadas en "Narrativa colombiana contemporánea" no pasaron inadvertidas para la historia literaria colombiana. Su trascendencia, su presencia y su actualidad se pueden apreciar en dos vías: la primera, en la importancia que se le ha dado a estas obras o a sus autores dentro del campo literario nacional, es decir, la consagración o canonización que hayan podido tener; y la segunda, en las nuevas ediciones (o reediciones) que han salido al mercado durante los últimos cincuenta años.

En Sesenta minutos de novela en colombiana, Uriel Ospina (1976) hacía un recuento, a modo de "cursillo" (p. 47), de los escritores colombianos más destacados en el ámbito novelístico. Esta selección incluía a Airó, Ponce de León, Rojas Herazo, Soto Aparicio y Buitrago. Aunque los dos primeros se destacaran por su labor como novelistas, anterior a 
las obras publicadas en Tercer Mundo, legitimaban la propuesta editorial de la colección "Narrativa colombiana contemporánea", en tanto ya tenían un nombre ganado como narradores. Los otros tres se destacaron por sus novelas: la obra de Rojas Herazo era señalada de "exuberante" por no acomodarse "en los marcos de conveniencia literaria" (Ospina, 1976, p. 149); Soto Aparicio era “un buen escritor" que en Mientras llueve demostraba ser "un excelente narrador" con "mucho camino por delante, si la fertilidad del autor mant[enía] el ritmo” que tenía hasta ese momento (p. 144); por último, Fanny Buitrago, desobediente a un orden narrativo impuesto, lo cual era "uno de los motivos de su éxito en la crítica y de su poco éxito de lectores en la base", presentaba una obra “moderna” " "audaz" "que sin duda dar[í]a mucho de qué hablar" una vez se liberara "de esos relentes de hacer literatura de rebeldía pequeño-burguesa” (p. 158). ${ }^{5}$

Los comentarios de Ospina no iban a ser más que el anticipo de una reiteración de calificativos y clasificaciones de unas obras y unos autores que desde el momento de su publicación harían parte del núcleo, como ya se dijo, más selecto de la narrativa colombiana hasta años recientes (Pineda Buitrago, 2012). Rojas Herazo y su novela Respirando el verano, por ejemplo, serían vistos desde entonces como un antecedente del García Márquez de Cien años de Soledad (1967), a pesar de haber sido opacados por este y la repercusión de su novela en el mercado internacional (Menton, 1978; Ayala Poveda, 1984). Otros valorarían su obra como el inicio y la representación de la novela moderna en Colombia (Williams, 1991), esto es "un quiebre en el desarrollo de la narrativa colombiana" (Pineda Botero, 2001, p. 147), en tanto ejemplo de la renovación de la novela tradicional. Al lado de esta, El hostigante verano de los dioses de Buitrago, resultado de "una actitud provocadora y desafiante" (Jaramillo, 1991, p. 346), también ha sido distinguida como parte de la modernización de la novela colombiana durante los sesenta (Ayala Poveda, 1984; Williams, 1991).

De igual modo, la valorización histórica y crítica de las obras de la colección también les ha dado su lugar a los cuentistas y a los dramaturgos. Antonio Montaña y Gonzalo Arango, quién ya tenía un lugar ganado en la historia literaria colombiana por su accionar dentro del movimiento nadaísta, han sido reconocidos por sus obras de ficción. Con Cuando termine la lluvia y Sexo y saxofón se ganaron un lugar entre los cuentistas más importantes de su generación (Pachón Padilla, 1988) y sus cuentos están 
incluidos en las antologías más importantes de este género en Colombia (Agudelo, 2015). Buenaventura, por su parte, ha sido considerado durante los últimos cincuenta años como el gestor de una nueva forma de hacer teatro. La fundación de una escuela experimental (el Teatro Experimental de Cali) permitió que su obra "A la diestra de dios padre”, incluida en el libro Teatro e inspirada en el cuento de Carrasquilla, se convirtiera "en una de las piedras angulares" de uno de los grupos dramatúrgicos más descollantes de la época en el ámbito nacional (González Cajiao, 1988, p. 720).

Finalmente, la trayectoria editorial de cada una de las obras de la serie "Narrativa colombiana contemporánea”, señalada en la Tabla 1, es muestra del trasegar de la colección dentro de la historia editorial colombiana y de la conservación de su valor literario, a pesar de que no todos los libros hayan tenido otras ediciones dentro del mercado literario. Mientras llueve de Soto Aparicio es hasta el momento la obra más editada desde su aparición en 1966 (al menos diez veces, contando ediciones y reediciones en varias editoriales). La siguen en su orden Respirando el verano (cuatro veces), El hostigante verano de los dioses (tres veces), Teatro de Buenaventura (tres veces, caso especial, pues las ediciones referenciadas son compilaciones que reúnen una o dos obras del libro original), Sexo y saxofón (dos veces), Los ratones van al infierno (una vez), La infancia legendaria de Ramiro Cruz (una vez) y El hombre que hacía monitos (una vez). De estas ediciones, es importante observar la frecuencia de publicación con la que aparecieron nuevamente disponibles para el público lector, debido a que en las décadas siguientes hubo al menos una nueva edición de alguna de las obras de la colección, lo que habla del valor que distintas casas editoriales les han dado a las mismas, año tras año. La trayectoria editorial de los libros de la colección muestra, de esta manera, cómo la aparición en el mercado de nuevas ediciones ha actualizado, para distintas generaciones de lectores, la importancia de la serie "Narrativa colombiana contemporánea" para la literatura colombiana.

\section{A modo de cierre}

El estudio de la colección "Narrativa colombiana contemporánea”, como ejemplo de transformación de una literatura en crisis, evidencia la apertura que le dio la editorial a nuevos materiales literarios dentro de un mercado que los exigía. Ediciones Tercer 
Mundo se definió, entonces, como una editorial que ofrecía colecciones únicas para el repertorio de la literatura colombiana. De ahí que no sea temerario afirmar que esta colección fue una respuesta al "subdesarrollo literario" colombiano (García Márquez, 1983, p. 313); más todavía si se tiene en cuenta que el marco general de esta colección era un catálogo, cuyo protagonista principal era el problema del desarrollo en esta parte del continente y sus implicaciones sociales para los países del mal llamado tercer mundo.

Asimismo, sin importar el acercamiento desde el cual se hayan estudiado las novelas y los aciertos o desaciertos de estos, se puede decir que a las obras de "Narrativa colombiana contemporánea" o a sus autores se las ha dado un lugar de relativa importancia dentro de las historias, manuales o estudios académicos sobre literatura colombiana. La mayoría de los autores promovidos desde la colección han sorteado el paso del tiempo. La crítica y la historia literarias han dado cuenta de su aparición como un fenómeno de transformación y renovación de los valores literarios en los años sesenta y el periplo crítico de las mismas en distintos trabajos aseguró la consagración y canonización actual de algunos de los textos publicados en "Narrativa colombiana contemporánea”. Cabe señalar que algunos autores y obras cayeron en el olvido. Como es evidente, la transformación de los valores estéticos y literarios es constante y solo algunos continúan figurando en el panorama del sistema literario. La lectura de manuales, historias y otros trabajos críticos de consulta obligada en asuntos de narrativa colombiana demuestra cómo desde los años setenta hasta la actualidad los autores y las obras de la colección se constituyen como referencias de determinados aspectos de la diversidad de la historia literaria colombiana.

\section{Referencias bibliográficas}

Airó, C. (23 de febrero de 1963). Nuestro quehacer literario. El pro y el contra de la novelística colombiana. Lecturas dominicales. El Tiempo, pp. 1-2.

Agudelo, A. M. (2015). Hacia una historia del cuento colombiano. Inti: Revista de literatura hispánica 81, pp. 147-169. Recuperado de: https://bit.ly/2ZcgGZa [15.08.2019]

Arango Ferrer, J. (1963). Dos horas de literatura colombiana. Bogotá: La Tertulia.

Ayala Poveda, F. (1984). Manual de literatura colombiana. Bogotá: Educar editores.

Bejarano, A. (2017). La utopía en la revista bogotana Espiral (1944-1975) de Clemente Airó. Nómadas 45, pp. 97-106. 
Bronx,H. (1966). Veinte años de novela colombiana. Medellín: Colección Academia Antioqueña de Historia.

Dubois, J. (2014). La institución de la literatura. Medellín: Editorial Universidad de Antioquia.

García Márquez, G. (1983). De Europa y América 2 (1955-1960). Bogotá: La Oveja Negra.

García Piedrahita, E. (1963). Teatro literario y literatura teatral. Lecturas dominicales. El Tiempo (16 de junio), p. 5.

González Cajiao, F. (1988). El proceso del teatro en Colombia. En G. Arciniegas y G. Zea. Manual de literatura colombiana (pp. 665-733). Bogotá: Procultura/Planeta.

Jaramillo, M. M. (1991). Fanny Buitrago: la desacralización de lo establecido. En M. M. Jaramillo, A. Robledo y F. M. Rodríguez-Arenas. ¿̨Y las mujeres? Ensayos sobre literatura colombiana (pp. 239-281). Medellín: Universidad de Antioquia.

Lecturas Dominicales (1963). Escritos y escritores: "Respirando el verano", Lecturas Dominicales. El Tiempo (10 de febrero), p. 4.

Llano Parra, D. (2015). Enemigos públicos. Contexto intelectual y sociabilidad literaria del movimiento nadaista, 1958-1971. Medellín: Fondo Editorial FCSH.

Madrid Malo, N. (1966). Estado actual de la novela en Colombia. Boletín Cultural y Bibliográfico 9 (6), pp. 1128-1133.

Marín Colorado, P. (2017). Novela, autonomía literaria y profesionalización del escritor en Colombia (1926-1970). Medellín: La Carreta Editores.

Menton, S. (1978). La novela colombiana: planetas y satélites. México: Fondo de Cultura Económica.

Moreno Clavijo, J. (1963). Los cuatro últimos libros de "Tercer Mundo". Lecturas dominicales. El Tiempo (14 de julio), p. 5.

Ospina, U. (1976). Sesenta minutos de novela en Colombia. Bogotá: Banco de la República.

Pachón Padilla, E. (1988). El cuento. Historia y análisis. En G. Arciniegas y G. Zea. Manual de literatura colombiana (pp. 511-588). Bogotá: Procultura/Planeta.

Pérez, S. (2018). Clemente Airó: el editor en el exilio de la Violencia en Colombia. En S. Pérez (Coord.). Escribir en el agua. Textos sobre literatura colombiana y latinoamericana (pp. 105-121). Medellín: Sílaba Editores.

Pineda Botero, A. (2001). Juicios de residencia: la novela colombiana 1934-1985. Medellín: Universidad Eafit.

Pineda Buitrago, S. (2012). Breve historia de la narrativa colombiana. Siglos XVI-XX. Bogotá: Siglo del Hombre Editores.

Rodríguez Amaya, F. (2014). De juglares y narradores en Colombia: los años Setenta, tan cerca y tan lejos de Macondo. En E. Corti y F. Rodríguez Amaya (Eds.). Periplo colombiano (pp. 5-30). Bergamo: Sestante Edizioni y Bergamo University Press. 
Rodríguez Garavito, A. (1963a). El mundo del libro. Boletín Cultural y Bibliográfico 6 (2), pp. 250-258.

Rodríguez Garavito, A. (1963b). El mundo del libro. Boletín Cultural y Bibliográfico 6 (2), pp. 836-846.

Rodríguez Garavito, A. (1964a). El mundo del libro. Boletín Cultural y Bibliográfico 7 (5), pp. 818-822.

Rodríguez Garavito, A. (1964b). El mundo del libro. Boletín Cultural y Bibliográfico 7 (8), pp. 1423-1427.

Rodríguez Garavito, A. (1967). El mundo del libro. Boletín Cultural y Bibliográfico 10 (12), pp. 123-127.

Soto Aparicio., F. (1964). Libros contemporáneos: "Cielos y gentes". Magazín Dominical. El Espectador (5 de abril), p. 15 b.

Téllez, H. (1963). La novela de Rojas Herazo. Lecturas Dominicales. El Tiempo (24 de febrero), p. 7.

Torres León, F. (1964). La cultura en Colombia, 1963-1964: arte, literatura, música y teatro. Boletín Cultural y Bibliográfico 7 (7), pp. 1239-1287.

Williams, R. L. (1991). Novela y poder en Colombia, 1844-1987. Bogotá: Tercer Mundo Editores. 